\title{
O Banquete musical d'A Barca do Sol
}

\author{
A Barca do Sol: musical banquet
}

\section{Yuri Behr Kimizuka}

Universidade de São Paulo, São Paulo, Brasil

yuribehr@usp.br

\section{Paulo Tiné}

Universidade de Campinas, Campinas, Brasil

paulotine@iar.unicamp.br

\begin{abstract}
Resumo: Dentro do contexto dos grupos de música alternativa e do rock progressivo brasileiro nos anos de 1970 , a Barca do Sol apresenta peculiaridades que que dialogam com o cenário musical da época e também com a produção musical dos grupos britânicos como Jethro Tull e Gentle Giant. 0 uso prioritário de instrumentos musicais acústicos, ambiguidades rítmicas e construções contrapontísticas estão presentes na canção Banquete, gravada no ano de 1976, que é examinada nesse artigo à luz das recentes interpretações sócio-musicológicas - sobretudo de Mathias Lundberg (2014) e Nick Braae (2011) - de maneira a problematizar as relações entre os elementos musicais e o momento em que esta foi gravada.
\end{abstract}

Palavras-chave: música alternativa brasileira; contraponto e métrica Irregular na música popular; $A$ Barca do Sol.

Abstract: Within the context of Brazilian progressive rock groups in the 1970s, A Barca do Sol brings peculiarities that dialogue with the musical scene of those days, and also with the musical production of British groups such as Jethro Tull and Gentle Giant. The preference for using acoustic musical instruments, rhythmic ambiguities and contrapuntal constructions are present in the song Banquete, recorded in 1976, which is examined in this article in the light of recent socio-musicological interpretations - mainly Mathias Lundberg (2014) and Nick Braae (2011) - in order to problematize the relations between the musical elements and the moment in which it was recorded.

Keywords: Alternative brasilian music; counterpoint and cross rhythm in popular music. A Barca do Sol.

Submission date: 30 March 2017

Final approval date: 2 April 2108

\section{1 - Banquete não Antropofágico}

No decorrer da década de 1970 houve na música popular um surgimento de estilos que, embora sejam em muitos aspectos diferentes, são unificados pelo que John Covach (2005) denomina por "estética hippie". Essa se caracteriza pela "ambição musical, tecnologia, virtuosismo, textos e álbuns conceituais" (COVACH, 2005 p.3). 0 termo rock progressivo compreende muitas ramificações e definições, o que torna o seu uso muito controverso. Porém, vários autores dedicados ao estudo do rock progressivo, como Macan (1997), Parentin (2011), e Lundberg (2014) concordam que este gênero musical tem origem no álbum Sgt. Pepper \& the Lonely Heart Club Band, dos Beatles. Isso reforça o argumento de Covach sobre a "estética hippie." 
Muito embora Covach esteja falando apenas do ponto de vista do musical, é certo que ele considera também os aspectos sócio culturais que são determinantes em qualquer estudo desse tipo. Além disso o fenômeno do rock progressivo ocorre simultaneamente em vários lugares, Alemanha, França, Escandinávia, e Itália, dentre outros; e cada um apresenta suas particularidades. Por isso cada contexto social implica diferentes características, muito embora é certo que existe um status quo que permeia aquela época como um todo. Tomemos como exemplo o que diz Parentin sobre o cenário progressivo italiano dos anos de 1970 para notar que o que ele descreve não difere muito de outros países.

\begin{abstract}
Muitas vezes na música daquele período pode-se respirar o ar da mudança, mas também a necessidade de escape da realidade e das suas mazelas diárias. Bem, nem todas as letras daquela "era" eram ao mesmo tempo altamente poéticas, mas de uma forma ou de outra o movimento do rock progressivo italiano foi a expressão de um compromisso artístico e social e deu voz a toda uma geração. (PARENTIN, 2011, p.15 tradução dos autores)
\end{abstract}

Sem dúvida é também possível estender essa afirmação, de que o rock progressivo é "a expressão de um compromisso artístico e social" da geração daqueles anos, independente do local. No Brasil, essa perspectiva estética proposta por Covach se faz notadamente presente, mas é preciso, porém, contextualizar também a palavra hippie, visto que a pesar dessa possuir o sentido correto, no que diz respeito ao movimento social e produção artística que remete ao "verão do amor" do ano de 1967, muitas vezes também possui uma conotação negativa. Portanto, a acepção do termo hippie que aqui se coloca está mais ligada a uma proposta de liberdade e criação independente. Trata-se de algo que, independentemente do gênero musical, estava presente na juventude do período.

Os jovens, e principalmente os roqueiros da época, buscaram uma ruptura dos discursos conservadores, dando início a uma "cultura marginal", também conhecida como underground. (SAGGIORATO, 2012, p.296)

Durante os anos de 1970 o Brasil vivia numa espécie de isolamento cultural em parte imposto pelo regime militar, mas em parte também pela escassez de recursos financeiros que dificultava a aquisição de equipamentos musicais e outros meios semelhantes aos usados nos Estados Unidos e Europa. Isso fez com que a criatividade muitas vezes fluísse mais para uma tendência acústica do que para o som eletronicamente processado. Não significa, entretanto que não houvesse processadores de efeito ou sintetizadores no Brasil, ou mesmo que isso fosse uma tendência geral, visto que alguns grupos como Os Mutantes, ou Vímana, optaram por uma sonoridade mais eletrônica.-Tudo isso colaborou para que a geração que produzia música alternativa no contexto brasileiro procurasse uma maneira própria de expressão. É dentro desse contexto que surgem os grupos de música alternativa no Brasil, dentre os quais destacase, nesse artigo, $A$ Barca do Sol. 


\section{2 - Uma Barca e seus tripulantes}

Em meados de 1973 surgia no Rio de Janeiro, um grupo chamado A Barca do Sol, formado inicialmente por dois colegas no curso pré-vestibular de arquitetura em Copacabana, Fernando "Nando" Carneiro e Maurício Costa. Ambos se reuniam à tarde na casa de Maurício para estudar, e nos intervalos sempre havia a oportunidade de tocar um pouco de violão. 0 irmão caçula dos Costa, Marcelo, acabava por juntar-se aos dois fazendo percussão. Desse início quase casual, ao fim do mesmo ano, resultou uma apresentação no auditório das Faculdades Bennet já com o nome de A Barca do Sol. No ano seguinte através de Egberto Gismonti, que era amigo da família de Nando, surgiu a oportunidade de Nando, Maurício e Marcelo participarem como bolsistas do Festival e Curso de Música de Curitiba. Embora tenha sido Egberto Gismonti um dos primeiros incentivadores do grupo, foi Dori Caymmi quem acabou por reunir os outros membros, como conta Nando Carneiro:

Mas foi com Dori que mostramos nosso trabalho e ele convocou alguns músicos presentes para participar. Entre eles estavam, Jaques Morelenbaum, Marcelo Bernardes (primeiro flautista d'A Barca e é ele que toca o primeiro LP), Marcos Stul (contrabaixista, da antiga Equipe Mercado) e José Roberto Rezende (violonista e guitarrista) que entrou ajudando na percussão. O Ritchie Court (flauta) e o Alain Pierre Magalhães entraram no final de 1974 para o lançamento do LP "A Barca do Sol". (CARNEIRO, 2017)

Marcos Stul acabou deixando o grupo por divergências de pensamento, visto que ele não estava completamente de acordo com o espírito de coletividade que viria caracterizar A Barca do Sol. Marcelo Bernardes havia ganho uma bolsa para o Conservatório de Paris e optou por esse caminho. Richie Court, porém, não permaneceu muito tempo, sendo substituído por David Ganc. Com essa tripulação A Barca permaneceu até 1981, quando cada um procurou navegar por suas próprias rotas e mares.

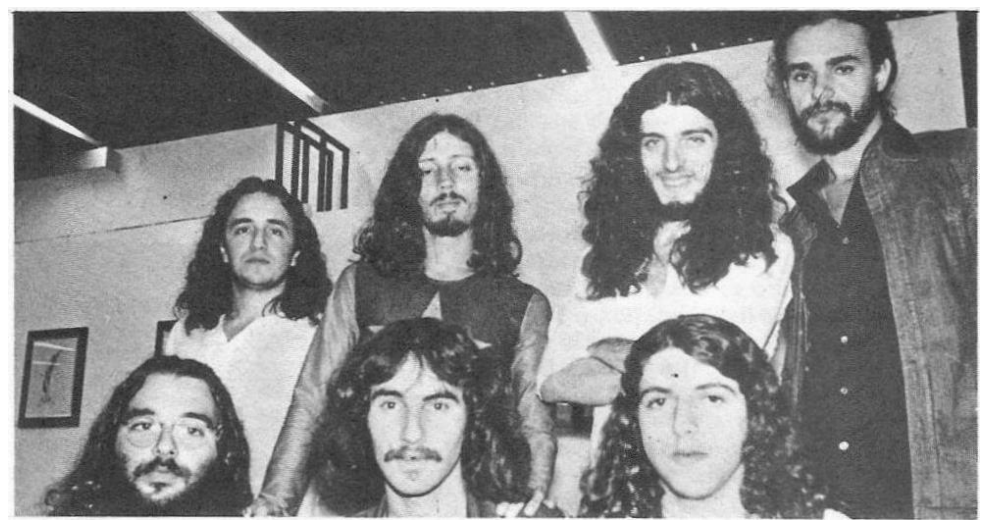

Figura 1: Integrantes d'A Barca do Sol em 1976. Em pé da esquerda para a direita: Beto Rezende (guitarra), Nando Carneiro (violão e voz), Mauricio "Muri” Costa (violão e voz), Alain Pierre (baixo acústico); sentados da esquerda para a direita: Jaques Morelenbaum (violoncelo e voz), David Ganc (flautas) Marcelo "Gordo"Costa (bateria e percussão

Enquanto permaneceram no mesmo barco o espírito de coletividade norteou a música do grupo, e por assim dizer, o estilo musical d'A Barca do Sol. Assim Nando Carneiro define essa questão:

Mas a realidade é uma coisa relativa a cada ser humano individualmente, eu também tenho a minha visão particular daquilo que seja a nossa maior riqueza, que é, sem dúvida, o nosso relacionamento humano e, o nosso relacionamento com o mundo e com 
o universo dos nossos amigos. Penso que essa vivencia somada àquilo que temos necessidade de extravasar resulta naquilo que a Barca diz. (Carneiro apud SÉRGIO, 1980, p.18)

Isso diz muito sobre como se forma a sonoridade desse grupo, pois as contribuições individuais são somadas nos mais diversos níveis. Não se trata apenas de relações musicais, mas também de experiências de vida. Se a música é, como afirmam os cânones da etnomusicologia, uma resultante do contexto social, $A$ Barca do Sol tinha plena consciência de seu papel. E ainda mais, a opção de não haver declaradamente um líder, ou um único estilo, é também uma proposta política e social em concordância com os temas, e o mundo literário ao qual estavam ligados, bem como a estética hippie.

\section{3 - Ligações perigosas: a poesia marginal}

Além dos membros efetivos do grupo não se pode deixar de mencionar os poetas que escreveram as letras das canções. Geraldo Carneiro, Cacaso ${ }^{1}$, e João Carlos Pádua, são os três principais nomes, muito embora o nome mais frequente seja o de Geraldo Carneiro. Estes estão inseridos num movimento literário brasileiro conhecido como poesia marginal ou "geração mimeógrafo 2 ". Dentre as características dessa geração destacam-se a recusa na forma experimental da poesia concreta, e uma temática ligada ao cotidiano - por vezes lírica e hermética - mas sempre com um viés crítico.

Num recuo estratégico, os novos poetas voltam se agora para o modernismo de 22, cujo desdobramento efetivo ainda não fora suficientemente perseguido. Nesse sentido, merece atenção a retomada da contribuição mais rica do modernismo brasileiro, ou seja, a incorporação poética do coloquial como fator de inovação e ruptura e com o discurso nobre acadêmico. (HOLLANDA, 1975, p.11)

Este distanciamento da poesia concreta é também, de certo modo, característica de um certo apartamento geográfico entre Rio de Janeiro e São Paulo. E sem qualquer bairrismo ou intenção de afastar culturalmente essas cidades, cada uma desenvolveu seu próprio perfil de resistência ao estado ditatorial e à cultura dominante. No caso do Rio de Janeiro surge a chamada poesia marginal, e seus autores que por lá circulavam. Embora, apenas algumas centenas de quilômetros separem essas duas capitais esse movimento e seus integrantes não se difundiu efetivamente em São Paulo, a não ser através da Barca do Sol, Olívia Byington, e Egberto Gismonti - que apesar de ser um músico de produção eminentemente instrumental, traz em suas poucas canções textos dos já mencionados poetas. A menção a essas cidades se deve ao fato de que a Geração Mimeógrafo é extremamente importante para a constituição estética, e como esta surge num contexto específico - o Rio de Janeiro dos anos de 1970 - é necessário enfatizar o por que HOLLANDA (1975, p.9) fazer questão de destacar que

\footnotetext{
${ }^{1}$ Pseudônimo de Antônio Carlos de Brito (1944-1987), que foi parceiro de Nando Carneiro em apenas uma canção: Cavalo Marinho.

20 termo "Geração Mimeógrafo" tem origem no fato de que os trabalhos não eram produzidos por editoras e sim pelos próprios artistas, muitas vezes valendo-se do mimeógrafo - dispositivo de cópia - tal como descreve Heloisa Buarque de Hollanda: "Alguns são mimeografados, outros, em offset, mostram um trabalho gráfico sabido e diferenciado do que se vê no design industrializado das editoras comerciais." (HOLLANDA, 1975 p.9)
} 
O próprio Tropicalismo, movimento anárquico, "popular" e agressivo, portanto, anunciando já um rompimento com a noção de cultura "culta", foi procurar sua legitimação artística através da vanguarda concretista de São Paulo”

É também necessário lembrar que os grupos paulistas como Os Mutantes, e Terreno Baldio, viriam trilhar um caminho musicais completamente diferentes, inclusive ao assumirem-se na categoria de rock progressivo. Isso não significa qualquer demérito em nenhum dos casos, o que se observa aqui são apenas as diferentes propostas e seus contextos históricos e sociais. Também é digno de nota que o tipo de contracultura e os elementos que irão dar origem a chamada "Vanguarda Paulista", na década de 1980, são diferentes. Reforça ainda este argumento pensar que a estética da poesia marginal é "uma nova forma de escrita que fosse, ao mesmo tempo, um contraponto à vanguarda concretista e à poética de João Cabral de Melo Neto, criticada por eles como sendo extremamente racional e objetivista". (MALUFE, 2006 p.20). É nesse sentido a relação temática e poética das canções d'A Barca do Sol divergem da produção cultural paulista.

\section{4 - Um som entre os oceanos}

Isso posiciona definitivamente $A$ Barca do Sol dentro do contexto sócio cultural brasileiro, sobretudo carioca daqueles dias, e marca uma grande diferença em relação aos grupos europeus. Assim A Barca, que traz uma produção musical muito particular sem perder o contato com o panorama da época.

Se em muitos pontos A Barca do Sol difere dos grupos europeus, musicalmente, há certamente outros em comum. Mas é preciso destacar ainda que qualquer referência direta da música d'A Barca do Sol ao rock progressivo constitui um reducionismo. Nos idos dos anos de 1970 praticamente no mundo inteiro houve alguma manifestação que veio a ser associada a este termo, e não se pode colocar na mesma categoria todos os grupos que de uma forma ou de outra apresentem alguma característica em relação a esse termo cunhado na crítica musical dos anos de 1970. Todos, de certa forma, àquela época possuíam certos elementos afins, mas isso não significa que sejam uma unidade estilística. Isso é o que MIDDLETON (1990, p.174) denomina por idioletic. Mesmo assim, é seguro dizer que algumas características são partilhadas por alguns grupos. Por exemplo, a prática de escrita polifônica está presente tanto n'A Barca do Sol quanto no britânico Gentle Giant. Em parte, isso se deve aos instrumentos envolvidos, visto que a presença de flautas e violoncelo são mais característicos deste tipo de escrita. Mas isso não relaciona efetivamente a música d'A Barca do Sol a qualquer gênero específico, tal como atesta Maurício "Muri" Costa em uma entrevista de 1976. "Nós não temos linha nem estilo. A nossa linha é exatamente não ter linha nenhuma. Acho que a música brasileira está sufocada entre o rock e o samba". (COSTA, apud REYS, 1978)

É uma tendência dos recentes estudos em música popular, como, por exemplo, LUNDBERG(2014), procurar contemplar não somente os aspectos socioculturais mas, também, a parte estrutural da música. Entretanto este tipo de abordagem costuma suscitar querelas quanto ao formalismo, que é negativamente associado a uma análise positivista. Porém, não se deve esquecer que a análise depende de como os dados são interpretados, e como se serve das ferramentas. 
O que se propõe é uma combinação de etnografia e análise formal para o estudo da música popular usando ferramentas e métodos da música erudita ${ }^{3}$, muito embora "não se possa alegar que a música popular possua o mesmo fundamento harmônico 4" (BRAAE, 2011, p.2 tradução dos autores), dentre outras peculiaridades. Entretanto, ao possuírem conceitos análogos sejam eles herdados ou não - possibilitam uma abordagem compartilhada. Por outro lado, querer impor a força da tradição sobre práticas, permeabilidades, e ainda sobre a etnografia, conduz a conclusões distorcidas. Por isso devemos ter claro ao analisarmos um trecho que se serve de um recurso composicional proveniente da música erudita, que não está em questão somente a técnica, mas todo o contexto de produção e recepção. Portanto é relevante considerar que o procedimento do fugato, por exemplo, contribui sobremaneira para estabelecer uma referência estilística.

\begin{abstract}
No fugato, vem mais ao caso o emprego de uma combinação contrapontística de elementos temáticos para criar a referência de uma art music do que o uso de maneira direta da harmonia tradicional e da condução de voz; mas em outras passagens pode ocorrer o uso nos padrões da common-practice de progressão harmônica e condução de vozes as quais podem desempenhar um papel crucial de modo a estabelecer a referência estilística5 ${ }^{5}$ (COVACH, 1997, p.11 tradução dos autores)
\end{abstract}

E esse fenômeno não se observa somente no caso do rock progressivo, mas na música popular como um todo, principalmente porque nesse caso existe uma diferença acentuada entre composição e arranjo. Esse último deve ser entendido tanto como parte integrante da composição, quanto como um fenômeno de experiência de grupo, uma vez que, não raras vezes, o arranjo é fruto de um processo de elaboração coletiva.

No âmbito da criação artística, aquilo que se denomina genericamente de "arranjo" diz respeito a uma série de procedimentos que incluem desde a harmonização de uma melodia dada (que pode variar de um arranjo para outro) até a escolha da instrumentação, do andamento e, em alguns casos da figuração rítmica da peça. (BESSA, 2012, p.4)

Isso se evidencia principalmente no caso do registro fonográfico, em que a música é o produto de uma elaboração que vai da composição da canção - texto e música - ao intérprete, passando pela produção de estúdio. Tudo isso nos remete outra vez ao álbum Sgt. Pepper and the Lonely Heart Club Band. A esse respeito Geraldo Carneiro (1978), um dos principais autores dos textos

\footnotetext{
${ }^{3} 0$ que se denomina aqui como "música erudita" é o equivalente ao temo em Inglês "common-practice", entendido como o tipo de produção musical, de matriz européia, do século XVII ao final do século XIX.

${ }^{4}$ popular music cannot claim to have the same hamonic foundation (BRAE, 2011, p.2)

${ }^{5}$ In the fugato it is more a case of employing a contrapuntal combination of thematic elements to create reference to art music than of overtly employing traditional harmony and voice leading; but other passages could be cited in which common-practice voice leading and harmonic progression are employed and in which detecting their presence plays a crucial role is establishing the stylistic reference. (COVACH, 1997, p.11)
} 
usados nas canções d'A Barca do Sol tinha muita ciência desse fato, tanto que na letra da canção ${ }^{6}$ "A Banda dos Corações Solitários" ele diz:

\author{
Não se ocupe mais em mascarar \\ o som atrás da velha medalha \\ cruz de honra da famosa e brava \\ banda dos corações solitários \\ Hoje zombo dos seus sonhos \\ Das canções sonhadas \\ Embora hoje ainda \\ Chore ouvindo suas baladas de amor \\ E guardando a ilusão de um certo verão \\ De anos atrás.
}

A primeira referência é explicita, visto que Banda dos corações solitários é uma tradução ipsisliteris de Lonely heart club band; e outra está na frase "e guardando a ilusão de um certo verão de anos atrás", na qual possivelmente se refere ao chamado "verão do amor" que aconteceu em 1967, ano em que foi lançado o álbum Sgt. Pepper. Muito embora essa canção, "A Banda dos Corações Solitários", nunca tenha sido gravada pela Barca do Sol, mas sim por Olívia Byington no seu primeiro disco, do qual $A$ Barca do Sol participa em quase todas as faixas. Por isso o texto dessa música é aqui citado porque porque reflete o pensamento poético e literário no qual o grupo se insere.

Em outra canção pode-se encontrar uma nova referência ao ano de 1967 e ao já mencionado disco dos Beatles, além de uma nova citação poética a Jimmy Hendrix que surge na canção Banquete:"E você cantando She is leaving home e Up from the sky, Uma canção gelada demais" (MORELENBAUM; CARNEIRO, 1976). Nesse caso, She is leaving home é a sexta música do lado A de Sgt. Pepper, e Up from the Sky é parte do álbum Bold as Love de Jimmy Hendrix, também do ano de 1967. Mas é preciso ter em mente que muito embora esse universo de rock permeasse Barca do Sol, os integrantes tinham consciência do quanto esse tipo de música era apenas uma dentre tantas outras coisas que ouviam e que $A$ Barca do Sol não era um grupo de rock.

\begin{abstract}
Não podemos negar o rock. Beatles e Jimmy Hendrix foram o desabrochar musical da rapaziada aqui. Agora um conjunto brasileiro tocando rock é como um grupo de russos querendo ser Os Originais do Samba. Ou um bando de japoneses tocando baião. Por mais perfeito, nunca vão ter swing. (COSTA apud EM, 1976)
\end{abstract}

Trata-se aqui não somente de uma alusão ao referido disco dos Beatles, mas também de uma recontextualização que, embora distante, é um dos pontos de partida. Juntamente com a escuta do rock também permeiam o universo outros tipos de manifestação musical que são igualmente

\footnotetext{
${ }^{6}$ A letra dessa canção não foi formatada como citação, no corpo do texto, para manter a versificação e a poética original.
} 
citações nas canções do grupo. Por exemplo em Hotel Colonial há uma menção textual a dois clássicos da música brasileira. Primeiro a Luar do Sertão, e depois a Chão de Estrelas, através da frase "Sem a cabrocha, o luar, e o violão". São referencias sutis, e que, ao contrário dos Mutantes - que havia feito uma regravação desta canção no ano 1970 - não é uma caricatura e nem uma releitura psicodélica.

Evidentemente, o pensar e fazer da música popular depois de Sgt. Peppers viria transformar a produção fonográfica mundial, e A Barca do Sol também acompanhou este momento que de certa forma colocam a gravação dos seus discos em pé de igualdade com o mainstream.

É sabido que na contracultura, no momento em que a art music europeia e música art music popular comercial, estavam para desaparecer como entidades separadas, e que os mais ambiciosos pós Sgt. Pepper - como os grupos já discutidos aqui - formam a nova síntese a partir do qual futuro música mainstream iria prosseguir7 . (LUNDBERG, 2014, p.2 tradução dos autores)

Este disco foi gravado também pela Continental, e a exemplo do anterior contou com críticas por parte da imprensa que fazia questão de enfatizar a qualidade musical dos seus integrantes e a importância da contribuição de cada um para construir a música do grupo. Porém, fica sempre evidente nas reportagens a dificuldade em se fazer um tipo de música que não está limitada a nenhum "estilo ou gênero". "A sobrevivência de um conjunto é uma questão de teimosia. Com cinco anos de existência ainda são apresentados como "um grupo novo", apesar de dois LPs solo e mais um, ainda inédito com a cantora Olívia." (AUTRAN, 1978) Esse trecho de reportagem do Jornal "O Globo" descreve bem a maneira como era recebido o trabalho d' $A$ Barca do Sol: sempre novo. Entretanto não se pode afirmar que o trabalho do grupo teve uma ampla aceitação e divulgação, não pela qualidade musical ou falta de empenho, mas porque há fatores externos que governam grande parte desse processo, tal como observa Carneiro:

E se a Barca não teve a aceitação que desejava foi talvez por não aceitar os esquemas do mercado, e as tramas para se tornar "número um das paradas musicais", enfim, os meios aos quais o mercado se habituou. (CARNEIRO, 2017)

Mas, de fato, essa não conformidade em se ater a qualquer gênero, mesmo que seja o próprio, torna o trabalho desse grupo interessante. Há uma unidade entre todos os discos, mas são todos diferentes. A cada momento tudo se transforma à medida em que novos elementos vão sendo incorporados, e no caso do álbum de 1976 - Durante o Verão - algo que chamou muita atenção, e que de certa forma ilustra essa mistura de ingredientes, é o encarte do LP ser em forma de cardápio.

\footnotetext{
${ }^{7}$ It is common notion in the counterculture at the time that western art music and commercial popular art music were poised to evaporate as separate entities, and that the more ambitious post Sgt. Pepper acts - such as bands discussed here - were the new synthesis from which future mainstream music would proceed. (LUNDBERG, 2014 p.2)
} 
Agora, depois de experiências na televisão e no cinema, está pronto o segundo LP, "Durante o Verão", com um encarte em forma de cardápio no qual as músicas são citadas como pratos de comida. (CARNEIRO apud EM, 1976)

Essa menção ao encarte aparece com frequência nas reportagens sobre este segundo disco do grupo, como que reforçando o caráter eclético e a elaboração de cada música deste disco.

A transformação na música mainstream nos coloca diante de um problema: se composição, arranjo, e principalmente a gravação são parte integrante da música, como analisar? Qual a relação entre esta música e a sua escrita? Evidentemente em cada caso há uma resposta diferente, muito embora, qualquer que seja o contexto, é difícil chegar a uma resposta satisfatória sem conhecer o processo de produção. Entretanto, no cerne desse fenômeno está a possibilidade de reprodução, o que leva à questão de apropriação da escuta de um registro fonográfico.

Finalmente, não é somente o processo de transmissão, mas também a análise que se beneficia com a repetibilidade da gravação. Assim, o musicólogo pode se concentrar em aspectos que antes não podia estudar, aspectos ligados à expressão tais como técnica instrumental, timbre, sutilezas de andamento, divisão rítmica e dinâmica, ornamentação, articulação, além, claro da improvisação. (ULHÔA, 2006, p.2)

A seguir iremos analisar um trecho contrapontístico da canção Banquete, gravada pela Barca do Sol em 1976 no álbum Durante o Verão.

\section{5 - Transcrição e Análise}

Se a reprodução eletro-mecânica possibilita ouvir indefinidas vezes o mesmo trecho, e até mesmo pular adiante e depois voltar, não há porque servir-se de outra linguagem para mediar a escuta. Na realidade, a escrita musical pode ser contestável em muitos sentidos, na medida em que também é possível refutar a obrigatoriedade da grafia de um discurso poético que se propõe à oralidade. Entretanto, se o escopo for analisar uma determinada estrutura, e sobretudo escrever sobre essa análise, a transcrição pode ser um recurso interessante por ser capaz de tornar visível certos aspectos sonoros. Sabemos que muitas partes dos arranjos d'A Barca do Sol eram escritos, o que também reforça a pertinência de se trabalhar com o suporte de notação musical. Optamos por uma transcrição por sua praticidade em termos analíticos, mesmo conscientes de sua limitação. Mas como o foco desta parte do artigo será os trechos contrapontísticos acreditamos que a linguagem musical, e sua escrita canônica, auxilia a compreender a estrutura a ser destacada. 


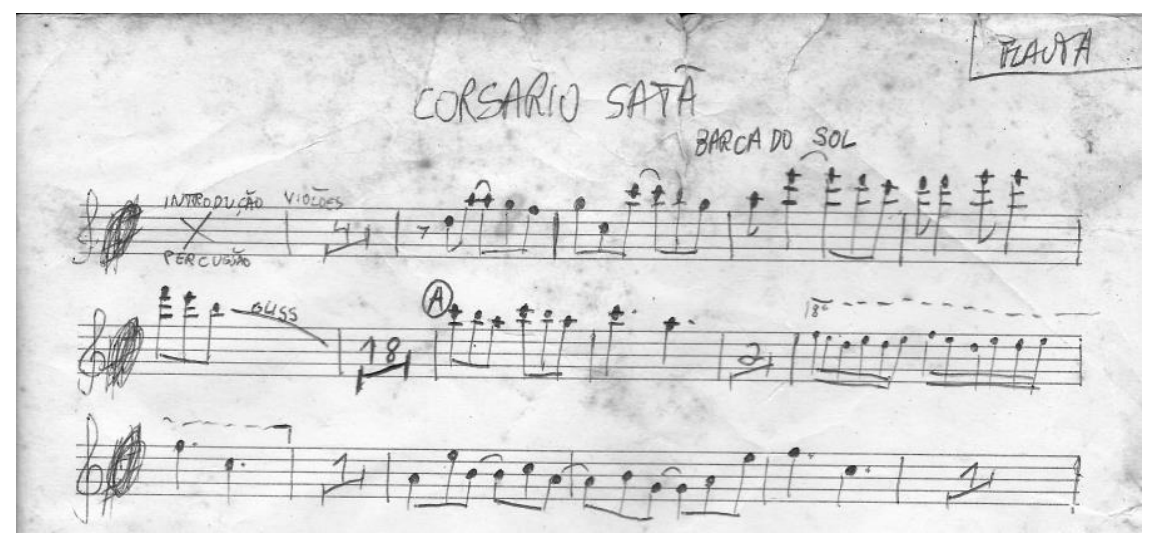

Figura 2: Trecho da parte de flauta da música Corsário Satã, em manuscrito, usada pela Barca do Sol (GANC, 1976).

Há diferentes possibilidades de escrita para se realizar a notação da divisão rítmica, algo que depende, por exemplo, da unidade de pulsação que se elege. Como existe, na gravação, um instrumento de percussão - um "coquinho" - que marca pulsos constantes, esta foi usada como referência. Após ouvir com atenção o trecho é possível constatar que este possui uma subdivisão em três. Ficou estabelecido então que a unidade seria uma semínima pontuada. Na figura 3 está a transcrição da linha melódica do violoncelo ${ }^{8}$ até a entrada da flauta.

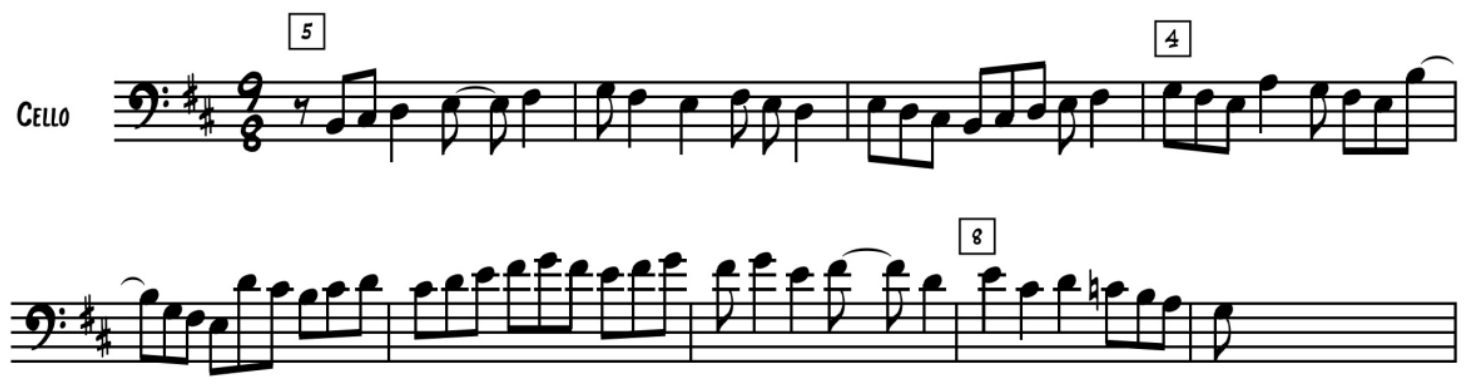

Figura 3: Banquete, transcrição da entrada do violoncelo, em 1'40"

Através dessa transcrição é possível constatar que existe um tipo de construção rítmica que, embora esteja circunscrita num padrão de compasso ternário, possui uma lógica irregular na sua subdivisão. Ou seja, em determinados momentos é possível perceber uma pulsação por semínima ao invés de semínima pontuada. Na figura 4 a tabela ilustra as relações entre as subdivisões binária e ternária nos três primeiros compassos da melodia do violoncelo. Os quadrados em preto representam os ataques a cada três colcheias, enquanto os quadrados em cinza marcam a cada duas colcheias. A partir desse esquema o que se observa é que os ataques da linha melódica descrevem uma alternância de subdivisão em relação ao pulso constante colcheia pontuada. Isso ocorre sistematicamente de tal forma que é até mesmo possível reorganizar a divisão alternando compassos de 3/8 e 3/4.

${ }^{8}$ Muito embora seja mais correto escrever para o violonecelo, nessa região, em clave de Dó na quarta linha, toda a parte do violoncelo está escrita em clave de fá no sentido de facilitar a leitura dos não violoncelistas. 




Figura 4: Esquema de comparação entre subdivisão binária e ternária dos três primeiros compassos.

Novamente a dúvida sobre a relação entre a análise e a transcrição vem à tona, pois esse é o tipo de abstração que geralmente decorre da escrita, através da qual se pode olhar mais facilmente para o que está acontecendo. Entretanto, valendo se da escuta, sem qualquer auxílio da notação, nosso ouvido nos coloca diante do impasse entre seguir uma pulsação que equivale a uma semínima pontuada ou ao invés disso a uma semínima. Isso, em grande parte, devido à fraseologia. 0 primeiro contraponto que há, nesse trecho é, portanto, rítmico. Uma única linha melódica que se contrapõe ao pulso de referência, como se pode constatar na figura 5.

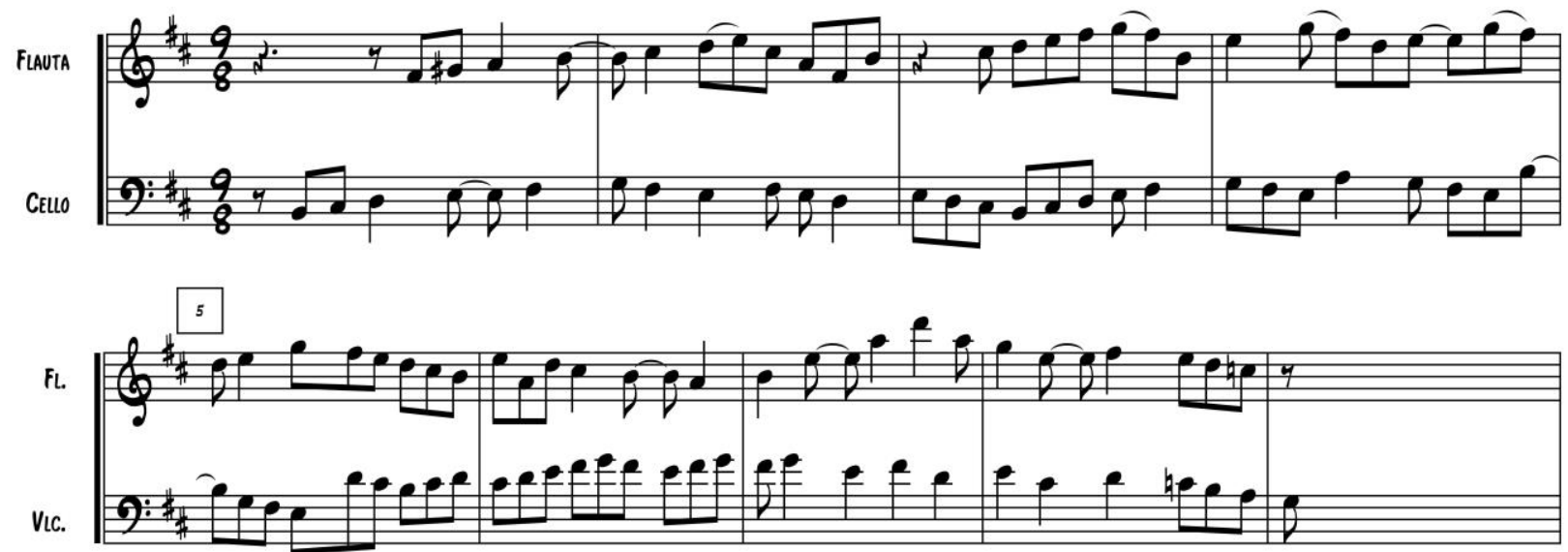

Figura 5: Banquete, contraponto entre violoncelo e flauta.

Mas isso não é sinal de que esta melodia foi construída pretensiosamente para emular um estilo "clássico", ao contrário. Este tipo de divisão rítmica é muito frequente nas músicas d'A Barca do Sol; seu princípio é a hemiola, uma prática bastante conhecida na música popular. Tomemos como exemplo, na figura 6, a introdução de Lady Jane que é provavelmente a música mais conhecida do grupo. 




Figura 6: Introdução de Lady Jane

Como se pode constatar na figura 6 , os compassos 5 , 7, e 8 podem muito bem ser lidos como se estivessem escritos em 3/4, isto é, ao assumirmos outra unidade de pulsação.

A construção melódica é modal - modo eólio - e as dissonâncias estão tratadas com certa liberdade estilística, visto que não seguem o estilo barroco nem o clássico. 0 que chama atenção, do ponto de vista melódico, nesse contraponto é a alteração de Dó\# para Dó natural, que do ponto de vista harmônico pertence ao acorde dominante de Sol maior, tal como ilustrado na figura 7. Esse tipo de alteração melódica, em parte herdado da música ficta do século XVI, não é de forma alguma estranha à música popular brasileira, sendo definido também como hibridismo popular.

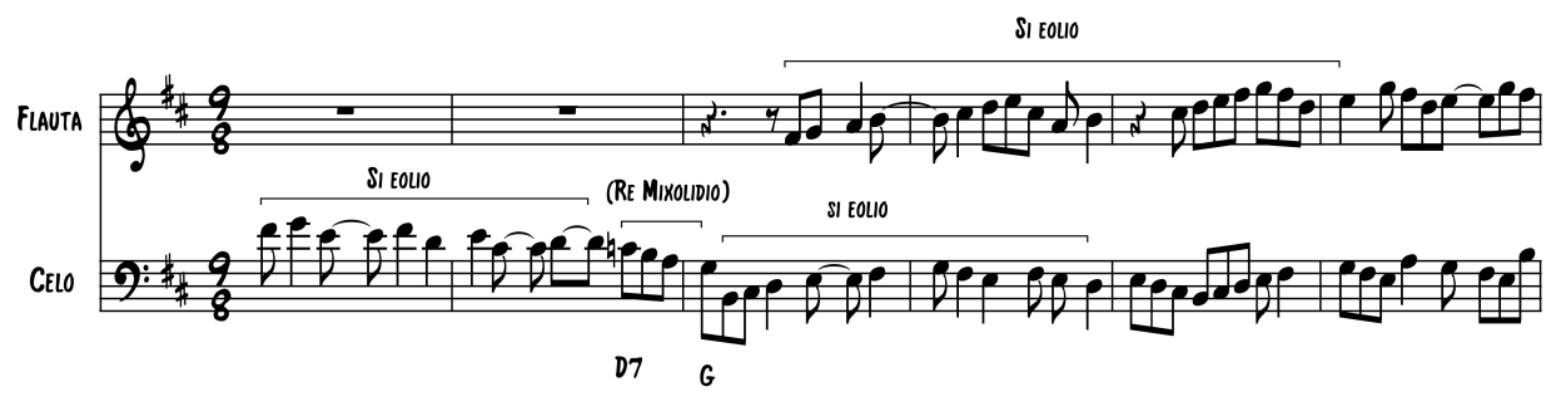

Figura 7: Banquete, destaque para a intercalação modal.

O violoncelo repete a sua melodia ao uníssono, e a flauta realiza um contraponto sobre essa melodia, ainda que possua fragmentos motívicos da melodia do violoncelo não se configura como uma resposta nos moldes de um fugato. Mas isso não invalida em nada a inventividade musical. Ao contrário, comprova a ideia de que o autor desse trecho, Jaques Morelenbaum, não procura fazer uma apropriação de um estilo fugato nos moldes clássicos. Essa parte contrapontística está completamente integrada ao arranjo como um todo, em sua grande parte, de elaboração coletiva. Isso demonstra que essa prática, e o resultado musical, estão inseridos no contexto da estética hippie, o que de fato se passa também no rock progressivo europeu. 
As técnicas de contraponto exemplificados nas duas músicas do Gentle Giant (bem como outras canções por uma série de outras bandas) até onde eu sei, nunca foram ridicularizadas e criticadas no contexto de contracultura, quer do ponto de vista estético ou ideológico9 ${ }^{9}$ (LUNDBERG, 2014, p.5 tradução dos autores)

O mesmo se pode dizer quanto aos procedimentos de composição e arranjo das canções da Barca do Sol. Muito embora a crítica jornalística tenha por vezes enfatizado que suas músicas não são de "fácil escuta", não há comentários que mencionem qualquer caráter elitista ou pretensioso. Por exemplo, estrutura rítmica analisada nesse artigo decorre também de uma espécie de diálogo, ainda que intuitivo, com a música tradicional latino-americana, tal como se lê na reportagem do jornal 0 Globo "Através do grupo $\mathrm{Agua}^{10}$ de repente descobrimos que os brasileiros também são sul-americanos e que a música andina é coisa tanto nossa quanto o samba". E por mais que analiticamente a elaboração de todos esses elementos se revele complexa, a matriz que unifica esses ritmos é afro-latina.

\section{5 - Conclusão}

Dentro do contexto musical brasileiro dos anos de 1970 e dos os diversos tipos de produção musical que se não se enquadram em nenhum gênero ou estilo pré-definido, ou que, optaram por não se limitar a qualquer denominação, $A$ Barca do Sol é sem dúvida uma referência. Ainda que recuse as influências advindas da cultura discográfica pós Sgt. Peppers, ou da estética hippie, a construção musical e poética a que $A$ Barca se propõe vai além dos limites da reprodução de motivos, sonoridades e discursos. A relação com a geração mimeógrafo confere às canções uma unidade estética no sentido de situá-las no contexto político, social, e cultural daqueles dias. Embora a poesia marginal tenha sido um movimento tipicamente carioca, os textos e a temática presentes nas músicas d'A Barca do Sol não guardam qualquer traço de localidade, dessa forma a Barca do Sol serviu também como um veículo de difusão para essa geração de escritores.

Os trechos das canções analisadas demonstram haver um processo criativo coletivo, mesmo que as músicas sejam assinadas pelos seus respectivos autores. Entretanto, como já foi argumentado anteriormente, o arranjo também faz parte do processo de criação, e no caso desse grupo isso ocorre através da soma das contribuições de cada integrante para criar um som único e sem definições de antemão. Ainda, de um ponto de vista analítico, se observa um jogo rítmico que desafia a métrica que, além de ser uma elaboração da construção musical, é também uma extrapolação da rítmica tradicional brasileira e sulamericana.

0 trabalho do grupo permanece aberto à investigação na medida em que não tem sido objeto de pesquisa no campo da música popular. Esse artigo tem exatamente essa intenção, a de inaugurar a perspectiva da pesquisa sobre $A$ Barca do Sol, no sentido de demonstrar suas

\footnotetext{
${ }^{9}$ The contrapuntal techniques exemplified in the two Gentle Giant songs (as well as other songs by a number of other bands) have, as far as I am aware, never been derided and criticized in a countercultural context, either from aesthetic or ideological perspective.

${ }^{10}$ Grupo chileno contemporâneo d'A Barca do Sol que atuou em diversos países da América Latina, inclusive o Brasil onde participou da gravação do disco Geares (1977) de Milton Nascimento. Deve-se observar que o contato com o trabalho do grupo Agua ocorreu apenas no ano de 1977 - três anos após o lançamento do primeiro disco d'A Barca do Sol. 0 que aponta para o fato de que as ditas semelhanças da música latino-americana são espontâneas, e não fruto de qualquer influência prévia.
} 
propriedades musicais intrínsecas e sua produção no contexto da época. Percebe-se que, através de sua proposta estética e tendência poética, a Barca realiza desleituras como, por exemplo, em Hotel Colonial com citações de "Luar do Sertão" e "Chão de Estrelas". Tomamos de empréstimo o conceito de desleitura da teoria formulada pelo crítico literário Harold Bloom aplicado à uma espécie de desconstrução no arranjo musical.

\begin{abstract}
...consiste numa versão contemporânea da atividade herética (...). Nessa perspectiva, o princípio central da tese bloominiana é que as relações revisionárias, ou seja, a influência entre grandes autores sempre ocorre mediante leituras fortes: o cerne desta desleitura reside no complexo ato crítico de interpretar dialeticamente mediante um processo que envolve a apropriação (revisão), a distorção (desvio) e a correção (redirecionamento) da doutrina original. (SILVA, 2016, p.193-194)
\end{abstract}

Assim, tais canções, escritas na belle epoque do Rio de Janeiro, contrastam com o aspecto sujo e urbano da década de 1970 (também presente em Lady Jane). Se, por um lado, isso os aproximava da poesia marginal, por outro, não se deve deixar de mencionar que, no Brasil, a Tropicália funcionou como uma espécie de porta de entrada da contracultura e, portanto, do rock. Assim a Barca, no contexto carioca, antecipa algumas das características da chamada vanguarda paulista: irrevrência, complexidade musical, urbanismo e desilusão com projetos estéticos pré-determinados.

\title{
Referências
}

1. AUTRAN, Margarida. Um som, mas que brasileiro, sul-americano: o da Barca do Sol. O Globo, Rio de Janeiro, p.35,12 de mai. de 1978.

2. BESSA, Virgínia Almeida. Apontamentos para o estudo do arranjo na música popular brasileira: história, fontes e perspectivas de análise, Anais do X Congresso IASP, Cordoba2012 disponível em http://www.iaspmal.net/wpcontent/uploads/2012/01/almeidabessa.pdf acessado em 07/01/2015

3. BRAAE, Nick. Formalism and Ethnography in Popular Music Analysis Anais do NZMS Conference, Welington, 2011 disponível em http://nickbraaemusic.files.wordpress.com/2013/06/braae-nzms-2011-paper.pdf acessado em $07 / 01 / 2015$

4. CARNEIRO, Fernando. Entrevista concedida a Yuri Behr. São Paulo 25 de mar. 2017.

5. CARNEIRO, Geraldo. A Banda dos Corações Solitários, in Olívia Byington. Corra o Risco. São Paulo: Continental, c1978. 1 disco sonoro. Lado A, faixa 1.

6. COVACH, John. Progressive Rock Understanding Rock: Essays in Musical Analysis. New York: Oxford University Press.

7. COVACH, John. The Hippie Aesthetic: Cultural Positioning and Musical Ambition in Early Progressive Rock Anais da International Conference "Composition and Experimentation in British Rock 1966-1976, Cremona, 2005. Disponível em http://www-3.unipv.it/britishrock1966-1976/pdf/covacheng.pdf acessado em 07/01/2015

8. EM disco e ao vivo os muitos sabores da Barca do Sol. O Globo, Rio de Janeiro, 22 de mai. 1976. P.33-34.

9. GANC, David. Corsário Satã. Rio de Janeiro. Partitura de flauta, grafada em 1974, da canção composta por Nando Carneiro e João Carlos Pádua. Partitura manuscrita. 
10. HOLLANDA, Heloísa Buarque. (org.) 26 Poetas hoje, antologia. Rio de Janeiro: Aeroplano, 2007. 6a Edição.

11. LUNDBERG, Mattias. "To Let it Be Without Pretense": Canon, Fugue, and imitation in Progressive Rock 19681979 Music Theory Online volume 20, number 3, September 2014

12. MALUFE, Annita Costa. Territórios dispersos: a poética de Ana Cristina Cesar. São Paulo: Anna Blume, 2006.

13. MIDDLETON, Richard. Studying Popular Music. Buckingham: Openmusic University Press, 1990.

14. MORELENBAUM, Jaques; CARNEIRO Geraldo. Banquete, in A Barca do Sol. Durante o Verão. Cidade: Gravadora, c1976 1 disco sonoro. Lado A, Faixa 5

15. NEM rock, nem samba, nem baião. $O$ canto geral da música. $O$ Globo, Rio de Janeiro, 7 de out. 1976. s.p.

16. MACAN, Edward. Rocking the Classics: English Progressive Rock and the Counterculture. New York: Oxford University Press, 1997.

17. PARENTIN, Andrea. Rock Progressivo Italiano: An introduction to Italian Progressive Rock CreateSpace, [S.l.] 2011.

18. REYS, Aloysio. A Barca do Sol. Jornal da Música n.19, 1976. n.p.

19. SÉRGIO, Paulo. A Aventura da Barca. Canja Quinzenal de Música 16 a 29 out. 1980. p.18-19.

20. SAGGIORATO, Alexandre. Rock brasileiro na década de 1970: contracultura e filosofia hippie História: Debates e Tendências - v. 12, n. 2, jul./dez. 2012, p. 293-302

21. SILVA, Haroldo Aparecido. ANGÚSTIA DA INFLUÊNCIA E DESLEITURA NA FILOSOFIA DA EDUCAÇÃO PRAGMATISTA: DEWEY, RORTY E LIPMAN. Educação e Filosofia, v.30, n.59, p.189-207, jan./jun. 2016

22. ULHÔA, M. T. A pesquisa e análise da música popular gravada. In: VII Congresso da IASPM-AL, Casa de las Américas - Havana, Cuba, Junho de 2006, em: http://www.hist.puc.cl/historia/iaspm/lahabana/articulosPDF/MarthaUlloaMPgravada.pdf acessado em $07 / 01 / 2015$

23. UMA aula de criatividade. Música, São Paulo, dez. 1976. p.10.

\section{Referências de Gravações}

24. BYINGTON, Olivia (1978). Corra o Risco, Olivia Byington (Voz) e A Barca do Sol. São Paulo: Continental (LP). 33 $\frac{1}{3}$ rpm, estéreo. 1-07-405-288.

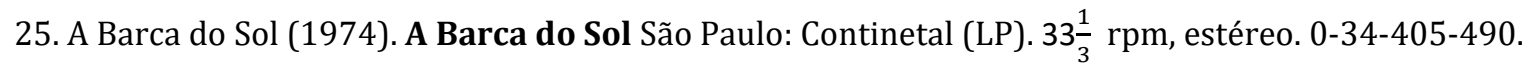

26. A Barca do Sol (1976). Durante o Verão São Paulo: Continetal (LP). 33 $\frac{1}{3}$ rpm, estéreo. 1-01-404-126.

Notas sobre os autores

Yuri Behr Kimizuka é compositor, regente e pesquisador. Doutorando na área de processos de criação musical pela ECA/USP, mestre em musicologia-etnomusicologia pela Universidade 
do Estado de Santa Catariana (UDESC). Desenvolve pesquisas na área processos de criação musical, composição assistida por computador (Open Music), e análise de fonogramas com estudos sobre a produção musical alternativa brasileira durante as décadas de 1970 a 1980.

Paulo Tiné é Docente do Departamento de Música do Instituto de Artes da Universidade Estadual de Campinas. Autor do livro Harmonia: Fundamentos de Arranjo e Improvisação em 2011 pela editora Rondó, com apoio da FAPESP (2a edição em 2014) e do álbum de partituras e CD "10 Peças para Violão: Solo brasileiro, anos 90" pela Rondó em 2016 (apoio FAEPEX). Lançou também os quatro Cds autorais sendo o último Novos Quartetos \& Canções em 2012 pelo selo Cooperativa de Música. 